\title{
Null Complement Anaphors as definite descriptions*
}

\author{
Alexander Williams \\ University of Maryland
}

\begin{abstract}
This paper develops the observation that, for many predicates, Null Complement Anaphora (NCA) is like anaphora with a descriptively empty definite description (Condoravdi \& Gawron 1996; Gauker 2012). I consider how to distinguish this sort of NCA from pronouns theoretically, and then observe an unnoticed exception to the pattern. For verbs like notice, NCA is neither like a definite description nor like a pronoun, raising a new puzzle of how to represent it.
\end{abstract}

Keywords: null complement anaphora, implicit arguments, definite descriptions, pronouns

\section{Introduction}

In using Ron won, Mo noticed, or Tipper is ready, we rely on context to say what Ron won, what Mo noticed, and what Tipper is ready for. These sentences all exhibit Null Complement Anaphora or NCA, to stretch the term somewhat. Commonly $\mathrm{NCA}$ is treated like reference with a pronoun or a demonstrative. But this, we will see, seems wrong. For many predicates NCA has the behavior not of a pronoun, but of a definite description. In section 3 I review the initial evidence for this from Condoravdi \& Gawron 1996. In section 4 I add further evidence from Gauker 2012, and then show that Gauker's analysis can itself be recast as a description theory of NCA. Developing this, sections 5 and 6 consider how to distinguish this kind of NCA from pronouns theoretically. I suggest treating such NCA as equivalent to a number-neutral definite description with no descriptive content. Reference succeeds, when it does, because of restrictions on its domain implied pragmatically by the sentential predicate. Finally in section 7 I observe that NCA with verbs like notice is not like a definite description. It has stricter requirements for antecedence, like a pronoun; but unlike both pronouns and descriptions, it resists bound readings in the scope of a quantifier. I finish by framing the puzzle of how to account for this.

* For discussion I thank Jeff Lidz, Valentine Hacquard, Michaël Gagnon, David Beaver, Roger Schwarzschild, Christopher Gauker, Jason Merchant, and the organizers and audience at SALT 22. The muddle that remains is my own. 
Williams

\section{Null Complement Anaphora}

Sentences (1-3) have a plausible initial paraphrase that adds a dependent with a pronoun in it. Both the sentence and the paraphrase require a context that provides a ready instantiation for the semantic relation $\Theta$ associated with that dependent. The paraphrase in (1a) adds a direct object associated with the role of a contest that is won; and either sentence, used as an independent clause, is felicitous only when a particular contest is somehow 'topical,' 'familiar,' or 'relevant' at that point in the conversation, in some sense to be explored below. The (b) sentences do not require a 'familiar' referent, and do not entail the sentence with NCA. They fail as paraphrases for this reason among others; see Gillon 2006 for careful differentiation.

(1) Ron won.

a. $\approx$ 'Ron won it.'

b. $\neq$ 'Ron won a contest.'

(2) Tipper is ready.

a. $\approx$ 'Tipper is ready for it'

b. $\neq$ 'Tipper is ready for a task.'

(3) Mo noticed.

a. $\approx$ 'Mo noticed it'

b. $\neq$ 'Mo noticed something.'

I say that such sentences exhibit "null complement anaphora" or NCA (Hankamer \& Sag 1976). Possible alternative names include "definite ellipsis" (Shopen 1973), "definite null complements" (Fillmore 1986), "implicit variables" (Partee 1989), "anaphoric implicit arguments" (Gillon 2006; Pedersen 2011), and "incomplete predicates" (Gauker 2012). Despite my choice of terms, I do not require that sentences with NCA involve a silent dependent in syntax. Nor do I require that the overt dependent in paraphrases be a DP or CP complement of the predicate (in (2) it is not). However, because it is convenient to do so, I will sometimes talk about NCA sentences as if they do involve a silent anaphoric expression that I call an NCA. This is just a way of talking about the understood instantiation or binding, however it may come about, of the implied semantic relation at issue $(\Theta)$.

NCA raises questions of grammatical representation because its availability is not decided just by the meaning of the predicate (Fillmore 1971, 1986; Shopen 1973; Hankamer \& Sag 1976; Dowty 1981). The verbs find out and discover have very similar meanings, for example, but only the former allows NCA, as (4) shows.

Ron won some yuan, but no one found out / *discovered. 
NCAs as Definite Descriptions

\section{NCAs as definite descriptions}

Pursuing insights in Dowty 1981 and Partee 1989, Condoravdi \& Gawron 1996 observe cases where NCA fails to have a paraphrase with a pronoun. These seem instead to have the felicity conditions of a definite description, anchored somehow to the local subject. Take (5) for example. This can mean than Lee won the contest in which she put chips on 17. So can (6), where the role of contest is instantiated by a definite description. But (7) cannot, where there is a pronoun instead.

(5) Lee put chips on 17 and won.

(6) Lee put chips on 17 and won the/her bet.

(7) \# Lee put chips on 17 and won it.

With a pronoun, the contest must be salient; typically, salience requires explicit prior reference. But with NCA this is not necessary. It is enough if the context, given world knowledge, permits the uncontroversial inference that there was a contest. The contest needs only to be "inferable" (Prince 1981) or easily "accommodated" into the domain of discourse (Condoravdi \& Gawron 1996).

For the same predicates, NCA patterns with descriptions also in the scope of a quantifier (Condoravdi \& Gawron 1996). (8) can be used to convey that every man won the contest in which he put chips on 17 , as can (9). ${ }^{1}$ But (10) cannot. So with either NCA or a definite description, it is enough that a referent is implied by the content of the quantifier's restriction, plus world knowledge. But this is not enough for a pronoun. The pronoun requires an explicit antecedent, as in (11). ${ }^{2}$

Every man who put chips on 17 won.

Every man who put chips on 17 won the bet / his bet.

$$
\text { \# Every man who put chips on } 17 \text { won it. }
$$

Every man who placed a bet on 17 won it.

1 We might say that (8) exhibits Mule Anaphora: a stronger breed of donkey, but phonetically sterile. 2 Pedersen (2011) disagrees with Condoravdi \& Gawron (1996), denying that win has an "anaphoric implicit argument," or NCA. His reason is that win permits an "indefinite" construal of the role of the prize, witness (i). But this observation does not establish Pedersen's conclusion, which pertains to the role of the contest, not the prize. It remains true that, absent contextual provision of a contest, Ron won is odd. Moreover, when both roles are made overt, as in (ii), the observed contrast between NCA and pronouns in the contest role persists. Finally, examples like (12) and (13) suggest that there are other examples which support Condoravdi and Gawron's perspective.

(i) Ron won, but I don't know what.

(ii) Every man who put chips on 17 won a prize (\#on it). 
Here are more examples. With NCA we can understand (12) as meaning 'applied for the job.' What is applied for is not the ad but the advertised job, not referred to explicitly, but implied in relation to the ad. This reading is difficult with the addition of for it, however. The sentences then seem to say that people applied for an ad, and not for a job. Likewise, with NCA the sentences in (13) are easily used to convey that the implied presentations were started early, while with a pronoun they are not.

(12) a. Mo saw an ad for dish washers and applied (?\#for it).

b. Every boy who saw an ad for dish washers applied (?\#for it).

(13) a. Lee was on the schedule of presenters, and she started (\#it) early.

b. Every student on the schedule of presenters started (\#it) early.

And while (14) can be used to mean that Ozzy was not ready for his performance, it seems that (15) can only be used to say that Ozzy was not ready for the festival. ${ }^{3}$ (The behavior of ready is admittedly subtle, however.)

Ozzy was up last in the festival, but he still wasn't ready.

Ozzy was up last in the festival, and he still wasn't ready for it.

NCA with the same predicates can also have a bound reading within the scope of a quantifier (Dowty 1981; Partee 1989; Condoravdi \& Gawron 1996; Francez 2010). The NCA is understood, not merely as covarying with the values of a bound variable, but as taking the very same values. Thus (16) and (17), read with NCA, can be understood as if the NCA roles were bound by every contest and no task respectively, just as they can be with the overt pronoun or description.

Every contest seems fair to the guy who won (it / the task).

No task is difficult for the guy who is ready (it / the task).

This does not show that NCAs are descriptions, since bound readings are available to pronouns as well. But the possibility of bound readings will be important in section 7. There we'll see that predicates like notice contrast with win or ready: they both forbid bound readings, and require more than an inferable antecedent. ${ }^{4}$

3 The contrast between NCA and pronouns is all the more remarkable for predicates that express relations to events, such as ready and start, since event pronouns do not themselves have a preference for an explicit nominal antecedent.

4 Condoravdi \& Gawron (1996) offer judgments to show that, unlike ordinary descriptions, "implicit arguments [NCAs] that anchor to the external context exhibit the referentiality property of pure indexicals." I do not share these judgments, however, and so will not try to account for the purported indexical readings in this paper. There is one way, however, in which NCA clearly does differ from overt definite descriptions. Like all so-called implicit arguments (Koenig \& Mauner 2000; ter Meulen 2004), NCA cannot by itself introduce a discourse referent for subsequent pronouns, (i).

(i) Ron won \#(the match). Sadly, that means Ross lost it. 
NCAs as Definite Descriptions

\section{Gauker on ready}

The observations above answer a recent challenge from Gauker 2012, concerning the interpretation of "incomplete predicates", a category that includes predicates with NCA. And while Gauker does not himself say this, his analysis is tantamount to one which treats NCA as a definite description, evaluated in a domain restricted by the local predicate. I will develop this view myself in sections 5 and 6 .

\subsection{Gauker's data}

The simple and dominant view is that "incomplete predicates" are semantically equivalent to predicates including pronouns or demonstratives, just quieter. Gauker objects to this view using the predicate ready, an example from Bach 1994b.

Gauker (2012: 66) observes that we have no trouble taking (18) to concern two different events. Tipper is ready for her task and $\mathrm{Al}$ is ready for his.

$$
\text { Tipper is ready and } \mathrm{Al} \text { is ready. }
$$

In my judgment there is a contrast here with pronouns. (20) is as good as (18) after (19a), taking Tipper and Al to be ready for two different events. But here the two events, both said to be interviews, fall under the same salient description. This is not so in (19b), and now I believe (20) seems worse than (18). The pair of (19b) and (20) effects no pragmatic asymmetry between the two potential antecedents. And in this circumstance there is pressure to resolve both it's the same way-if not to the same individual, then to tokens of the same salient type. NCA contrasts in not being equally sensitive to this pressure.

a. Tipper has an interview and Al has an interview.

b. Tipper has an interview and $\mathrm{Al}$ is going on a trip. Tipper is ready for it and $\mathrm{Al}$ is ready for it.

Such facts suggest treating NCA like a demonstrative. But Gauker (2012: 65) gives (21) and (22) as evidence against this. (21) readily escapes contradiction. It is enough for the context of use to provide two distinct targets for the two token demonstratives (two things pointed at, so to speak). But this is not enough to rescue (22). It escapes contradiction only if used to imply that there are different standards of application for the predicate ready: by one Tipper counts as ready, but by another she doesn't. This construal is not so much as suggested by (21), with the two demonstratives.

(21) Tipper is ready for this and Tipper is not ready for that.

(22) $\perp$ Tipper is ready and Tipper is not ready. 
These data can be accounted for if NCA with ready is like a definite description, relativized (at least) to the subject. Like (18), (23) allows that Tipper and Al are ready for two different events, with descriptions explicitly relativized to the subject. And like (22), (24) has the sense of contradiction.

Tipper is ready for her event, and Al is ready for his event.

$\perp$ Tipper is ready for her/the event and Tipper is not ready for her/the event.

\subsection{Gauker's analysis}

Gauker does not himself say that NCAs are like definite descriptions. But this is implied by his analysis; or at least by the modification of it that I will present here, starting with (25).

(25) Tipper is ready, used in conversation $c$, is true iff:

a. for some $\mathrm{X}$ : Tipper is ready for $\mathrm{X}$ and it is relevant in $c$ that Tipper is ready for $X$,

b. and for no Y: Tipper is not ready for $\mathrm{Y}$ and it is relevant in $c$ that Tipper is not ready for $\mathrm{Y}$.

(25a) says that NCA implies an existential quantifier. It also limits the scope of the quantifier to just those Xs that make it "relevant" that Tipper is ready for X. "A proposition is relevant in a conversation, in my sense," writes Gauker (2012: 79), "if and only if it is one that the interlocutors ought to take account of in order to achieve that which they are trying to do by means of their conversation." This relativizes the implied reference to the subject, and so explains (18). There is an X that makes it true and relevant that Tipper is ready for $\mathrm{X}$, and an $\mathrm{X}^{\prime}$ that makes it true and relevant that $\mathrm{Al}$ is ready for $\mathrm{X}^{\prime}$. These may be two different events, her task and his task. ${ }^{6}$

(25b) explains (22). It says that if Tipper is ready is true, then there is nothing for which Tipper is not ready, nothing that makes it relevant that Tipper is not ready for it. This implies that Tipper is not ready is false, and so makes (22) a contradiction.

Here I would like to modify Gauker's execution of this relevance condition, and treat it instead as a restriction on the domain of the quantifier. The truth condition

5 What Gauker actually proposes is to evaluate all sentences relative only to the subset of propositions in a world that are in his sense "relevant." This has the consequence, to me unattractive, that all irrelevancies lack a classical truth value. I therefore treat Gauker's relevance restriction as an explicit condition in the interpretation just of certain predicates. This affects many issues that Gauker considers important-but it helps me to compare Gauker's analysis with others.

6 To handle occurrences of Tipper is ready in the scope of quantifiers (and other operators) Gauker's notion of "relevance" will need to apply not just to the speech context, but to alternative 'contexts,' such as those represented by the scope of the quantifier under each value of the bound variable. 
NCAs as Definite Descriptions

(25a) then says just that, for some X, Tipper is ready for X. Likewise for (25b). But the use of NCA also signals that the quantifier is to be evaluated relative to a subset of the universe, comprising those things that make "relevant" the proposition expressed by its scope. I return to this in section 6 .

And now notice, with this revision (25b) amounts to universal quantification over the "relevant" domain for 'Tipper is ready,' provided we assume (26). (26) is an instance of the reasonable thought, endorsed by Gauker (2012: 81), that if either $P x$ or $\neg P x$ is "relevant," then both are. It's "relevant" whether $P x$.

$$
x \text { makes } P x \text { "relevant" if and only if it makes } \neg P x \text { relevant. }
$$

Given (26), the same Xs that make it "relevant" that Tipper is ready for X also make it "relevant" that Tipper is not ready for X. (25b) then requires that Tipper cannot fail to be ready for any of these; she must be ready for all of them. This makes a prediction. If Tipper's readiness is equally "relevant" in relation to two distinct events, we expect that Tipper is ready will be understood as 'Tipper is ready for both.' And indeed, this is the only natural interpretation of (27). ${ }^{7}$

Today Tipper will do two things: debate Jello and dine with Al. And Tipper is ready.

As modified here, therefore, Gauker's theory renders NCA as a universal quantifier over a restricted domain said to be non-empty. And this is of course, at bottom, the semantics of a number-neutral definite description, treated as a quantifier (Barwise \& Cooper 1981). I will follow this lead in sections 5 and 6, with emendations I now motivate.

\subsection{Challenges for Gauker}

Most of Gauker's analysis strikes me as right. But some of it does not. I will discuss three concerns, with the purpose of indicating some facts that any theory of NCA should take into consideration.

7 When two things are not equally topical, NCA is readily taken to refer only to the one that is more topical: (i) can mean that Tipper is ready to debate Jello. This is unsurprising; the same is true of overt descriptions, like the match in (ii) (McCawley 1979; Lewis 1979; Westerståhl 1985; Cooper 1996). But it is important, and it adds to the difficulty of distinguishing descriptions from pronouns theoretically. Unfortunately I can say nothing to resolve this issue here.

(i) Today Tipper will debate Jello after her lunch with Al. And she's ready.

(ii) Ron had a match after his match with Don, and he won the match. 
My first concern is the structurally limited scope of Gauker's relevance condition. Under Gauker's analysis, $\mathrm{X}$ is in the NCA domain for Tipper is ready if it makes relevant 'Tipper is ready for X.' Only the ready clause matters. Arguably, however, the whole sentence may matter. Consider (29) and (30), following on (28).

(28) Mo had a karate match and a math competition.

(29) Her sensei thinks she won, but her geometry tutor does not think she won.

(30) Her sensei thought she was ready, but her geometry tutor did not think she was ready.

In (29) and (30) the two instances of NCA can have different referents, the karate match versus the math competition. Intuitively the reason seems clear. The thoughts of the sensei may pertain only to the one, while those of the math tutor pertain only to the other. So what shapes the domain for NCA here is not just the ready clause, but also the higher clause with think. Gauker seems to be missing a generalization: relativizing to the clause is merely a subcase of relativizing to the sentence. This in turn suggests that the relevance condition is not part of the semantic axiom for the NCA predicate itself. It seems rather to be part of a general, sentence-level process of domain restriction for reference resolution; see section 6.

Second, a remark on the standards of "relevance." (31) says that Ozzy is ready for the concert but not for stardom.

(31) a. After this concert, Ozzy's gonna be a star.

b. It starts in five minutes,

c. and he's ready,

d. but he's not ready for the stardom to follow.

For Gauker, the truth of (31c) entails that no X makes it "relevant" that Ozzy is not ready for X. So Gauker must say that, when (31c) is evaluated, the content of (31d) is not "relevant." Yet this seems too strong. It does seems relevant to the conversation at that point that Ozzy is not ready for stardom. All we should want to say instead, I think, is that, since (31b) is about the concert, the concert is a distinguished target for anaphora in (31c) (see note 7).

Finally, a concern about the scope of negation. If NCA implies a quantifier, the quantifier must be made to scope over negation: Tipper is not ready entails that there is something Tipper is not ready for. But this would not follow if Tipper is ready were false whenever it is not true (presuming as usual that $\neg \phi$ is true exactly when $\phi$ is false). Accordingly Gauker (2012: 76) defines the falsity of Tipper is ready separately from its truth. And in the falsity conditions the quantifier takes scope over a negation: Tipper is ready is false only if there is an $X$ such that it is both true 
NCAs as Definite Descriptions

and relevant that Tipper is not ready for $\mathrm{X} .{ }^{8}$ An alternative response would be to reject the quantifier analysis outright. We can instead treat the implied description in Fregean style as a singular term that stands for the individual(s) satisfying its descriptive content. I prefer this response and will assume it in subsequent sections.

\section{NCA and pronouns}

How is NCA to be represented, then, in distinction to anaphora with pronouns?

In the interests of locating a minimal contrast, it is helpful to discuss this in the context of theories that treat anaphoric pronouns themselves as definite descriptions (Cooper 1979; Heim 1990; Neale 1990; Elbourne 2005). Under these theories, an anaphoric pronoun means 'the $\phi$,' with gender features adding presuppositions. Such pronouns differ from ordinary descriptions in having an unresolved reference condition, $\phi$, with no interpretation absent a context. This is resolved anaphorically, either by a prior noun (Elbourne 2005) or by a salient noun meaning (Cooper 1979). So (32a) means (32b), and $\phi$ is resolved as 'bet', (32c).

$$
\begin{aligned}
& \text { a. Every man who placed a bet on } 17 \text { won it. } \\
& \text { b. 'Every man who placed a bet on } 17 \text { won the } \phi \text {.' } \\
& \text { c. } \llbracket \phi \rrbracket^{c}=\text { 'bet' }
\end{aligned}
$$

In this setting the terms of our question are sharper. Why the contrast between (8) and (10) if pronouns and NCAs are both like descriptions?

(8) Every man who put chips on 17 won.

(10) \# Every man who put chips on 17 won it.

For description theories of pronouns, (10) represents a failure of antecedence for $\phi$. There is no noun bet and no explicit mention of a bet, so the intended resolution of it isn't available. Let's suppose this is the right diagnosis. The same problems do not beset NCA in (8). So we can infer that NCA descriptions are not unresolved. They must not depend in exactly the same way on the context to provide a reference condition. The meaning of Ron won must not be 'Ron won the $\phi$ ', with $\phi$ valued by the syntactic or discourse environment. ${ }^{9}$

8 Given this, both Tipper is ready and its negation entail that the domain for NCA is not empty. When it is empty, the sentences lack a classical truth value. Again, this is as with definite descriptions.

9 Interestingly, Dowty (1981: 89-90) builds on Cooper's (1979) description theory of pronouns in an early argument for treating NCA like a description. Translating (iia), below, with a free variable would not account for its "de dicto" interpretation as a response to (i).

(i) Have you found an apartment yet?

(ii) a. No, I'm still looking. 
The most spare hypothesis is therefore that, in the semantics, NCA descriptions have no descriptive content at all. For example, in any context Ron won just means 'Ron won the thing(s),' here using thing $(s)$ pleonastically in the informal metalanguage. We might represent this as in (33), using self-identity as an extensionally trivial condition.

$$
\text { Won }(\operatorname{Ron},[\imath y(y=y)])
$$

Take " $l y(P y)$ " to be a number-neutral Fregean definite description. It presupposes that its domain $\mathscr{D}_{P}$ has a non-empty extension $\llbracket P \rrbracket^{\mathscr{D}_{P}}$ for $P$, and then stands for the sum of $\llbracket P \rrbracket^{\mathscr{D}_{P}}$ 's members. Since $P$ in (33) is trivial, the NCA here just presupposes that its $\mathscr{D}$ is not empty, and then has the sum of $\mathscr{D}$ as its extension. ${ }^{10} \mathrm{I}$ think it is correct to treat NCA as number-neutral; see (27). But sometimes I will write as if NCA were singular, and thus as if it presupposes that $\mathscr{D}$ is a singleton.

I would like to say that this minimal hypothesis is correct. But it looks quite wrong on the face of it. Plainly NCA does not refer to everything in the universe of discourse, or even in the set of topical individuals; nor does it require that this set be a singleton. The hypothesis thus renders NCA as an egregiously 'incomplete description,' with a reference condition that is far too broad. This cannot be fixed by treating NCA as unresolved, lest we confound NCA with pronouns. So if the hypothesis is to be correct, the domain for NCA has to be narrowed substantially. Following on my revisions of Gauker 2012 in section 4.3, I suggest in the next section that this follows general sentence-level processes of reference resolution.

First a technical note on bound readings. There are various ways to implement covariation of a description with a quantifier $\mathscr{Q} x$ (Heim 1990, 1991; Neale 1990, 2004; Heim \& Kratzer 1998; Elbourne 2005). Very roughly, all have the outlines of (34). The bound variable $x$ occurs within an argument $\langle\ldots R y x \ldots\rangle$ of the description operator $\imath y$, related to $y$ by some relation $R$. In (35), where the donkey covaries with nobody, $R$ is the relation of being owned by $x$. And when the description has a bound reading, $R$ is set to identity. So in (36) the donkey is interpreted as 'the donkey that is identical to $x$,' where $x$ is bound by no donkey. See Elbourne (2005: 112-115) for comparison of ways to achieve this result.

$$
\mathscr{Q} x[\ldots l y\langle\ldots R y x \ldots\rangle \ldots]
$$

\footnotetext{
b. \# No I'm still looking for it.
}

So Dowty translates it instead as 'looking for the $\phi$,' and suggests that "a salient value for $[\phi]$ would be the property of being an apartment that the speaker will rent." But this reintroduces the confound of NCA with pronouns. Why does (iib) resist the "de dicto" reading, when by assumption it can have the same translation, 'looking for the $\phi$ '? I think the present account fares better. On Fregean descriptions in intensional contexts, see Elbourne 2010.

10 See Gillon 2006, 2011 for lucid discussion of how to represent the relation between occurrences of a verb with and without NCA. 
NCAs as Definite Descriptions

Nobody who loves a donkey beats the donkey.

No donkey is beaten by anybody who loves the donkey.

\section{NCAs as incomplete descriptions}

As Evans noted (1982: 312fn), "[o]ften the predicate does more to narrow down the range of possible interpretations of the referring expression than does the referring expression itself." In this spirit Condoravdi \& Gawron propose that "contexts for [NCA] are those that entail, or can be extended (via accommodation) so as to entail, the existence of an entity that satisfies the selectional restrictions imposed by the predicate for that argument" (1996: 10). But there is much more to be said.

The sorts of properties typically called "selectional" are too broad to adequately narrow the NCA domain. What do ready or start select for? Perhaps just an event. But neither one demands a context with just a single event, or applies to every event in the topical context. The domain must be winnowed down further, in ways much more peculiar to the individual predicate. Consider (37).

Tipper will be interviewed by Oprah this afternoon. But the clock is about to strike 2, the stylist is napping, $\mathrm{Al}$ has to prepare for his own interview this evening, and Tipper is still not ready.

This discourse makes several events relevant. Yet we quickly infer that Tipper is not ready for the interview in particular. The reason is, it is only the interview for which it is plainly consequential how Tipper is disposed to respond. The other events are very much relevant to the point of the conversation, since they all make it harder for Tipper to get ready by showtime. But it is less plain that it matters how Tipper might respond to them. So with ready in particular, we ignore those events in resolving NCA. The NCA domain for Tipper is ready comprises at most the Xs for which there is some conversational point to saying whether Tipper is ready for X, and this will exclude events whose effects on Tipper do not depend on her response. ${ }^{11}$

But just refining the restrictions of the lexical predicate is still not enough. The NCA domain is also restricted by the dependents of that predicate. Ron won is felicitous in (38) because its NCA ranges only over contests that involve Ron.

Ron had a match this morning, and Don had one too. Ron won.

And it does not stop there. From the sensei and the tutor in (29) we learned that higher clauses may also matter. The domain for NCA is relativized not merely to the governing predicate, nor to the clause it heads, but to the entire sentential predicate.

11 A meteorite hits Lop Nur. Mo has no response, but the impact also has no effect on her in Springfield. It would be odd to say she was ready for it, and also to say she wasn't. But now a large asteroid hits the same place, darkening the Earth for years. Mo has no response and starves. She was not ready. 
This makes our minimal hypothesis more plausible. At most a small portion of the needed restrictions on NCA reference derive from the meaning of the governing predicate; the bulk comes from general pragmatic factors in reference resolution, operating over whole sentences. Consequently it is plausible that this is the provenance of all the needed restrictions. Moreover, as we will see now, NCA again patterns with overt descriptions, not pronouns, in being specially sensitive to these factors. With descriptions but not pronouns, the supplement of sentence-internal content may be sufficient to support reference, when sentence-external context is not. This is most striking with very spare descriptions, such as the guy or the thing, which differ little from he or it in the reference conditions they provide lexically.

First consider (39) (ter Meulen 2004). The first clause implies that someone washed Jane's car, other than Jane herself. Reference to this car-washer then succeeds in the second clause, under the meager description of the guy. It succeeds because the domain for the description is restricted by the sentence that contains it. The guy must be the car-washer, because there would normally be no point to saying how well the car was washed by anybody else. In contrast, however, the same inference is not enough to support the pronoun in (40), without some guy anteceding it.

(39) Jane had her car washed. The guy did a good job.

(40) Jane had her car washed \#(by some guy), and he did a good job.

Stone \& Webber (1998) discuss examples like (41), adapted from Haddock 1987 and Dale \& Haddock 1991. On the face of it, the thing and the hat need a context with just one thing and just one hat. Yet (41) is felicitous even when the topical scene includes many things and many hats, all equal targets of attention. It is necessary only that the scene have just one hat with anything in it. ${ }^{12}$

(41) Take the thing out of the hat.

What does the trick is the clausal predicate. Any event of taking $\mathrm{Y}$ out of hat $\mathrm{Z}$ has the precondition that $\mathrm{Y}$ be in hat $\mathrm{Z}$ to start with. We use this condition to restrict the domains for the definites in (41), limiting them so that it may be satisfied. As a result the thing is tantamount pragmatically to 'the thing in some hat' and the hat, to 'the hat with something in it' (see note 14). But again, the inference is less supportive of a pronoun. (42) is far worse than (41), under the same circumstances.

(42) \# Take it out of the hat.

Sentences like (43) (McCawley 1979; Lewis 1979; Westerståhl 1985; Cooper 1996), adapted from Neale 2004, can be viewed in the same light, perhaps profitably.

12 I thank David Beaver for noting the relevance of this observation in the present setting. 
NCAs as Definite Descriptions

Any vote involves those who can vote and those who can be voted for. At a boxing match these are the judges and the boxers. This 'precondition' accordingly narrows the domains in (43). The subject denotes among the judges, and the object, among the boxers.

At the gold medal fight, the Russian did not vote for the Russian.

We can expect the same strategies to guide the construal of description NCA. As with overt descriptions, the domain will be restricted to just those things in (or accommodable to) the context that are relevant values for its sentential predicate $S .{ }^{13}$

Generalizing, the relevant values are those $x$ 's for which there would be a conversational point to asserting $S x$. And when there would be a conversational point to asserting that $S x$, I assume that there would also be a point to asserting that $\neg S x$. The same goes for commanding that $S x$ or requesting to be told whether $S x$. As a consequence, only some aspects of $S$ 's content will narrow the domain for $x$, since only some will make it pointless to assert or command its negation.

This includes at least the semantic presuppositions of $S$, since by definition these survive negation. It would be pointless to demand that Mo not stop eating, for example, if she wasn't eating already. Recently Champollion \& Sauerland (2011) have drawn important attention to the role played by presuppositions of the clausal predicate in restricting the domain for definite descriptions. ${ }^{14}$

But it is not only presuppositions that matter. (44) entails (46), and this restricts

13 The difference between (i) and (iii) illustrates the relative insensitivity of pronouns to the guidance of sentential context, in comparison to NCA. One likely response to (i), said out of the blue, is (ii). This shows that it's natural to resolve a pronoun to a salient referent, even when that referent does not suit the predicate. But not so for NCA. (ii) strikes me as a highly unlikely response to (iii). Natural here would be (iv), signalling an effort to accommodate a contest.

(i) I went to the faculty meeting and won it.

(ii) How do you win a meeting?!

(iii) I went to the faculty meeting and won.

(iv) Do you play some sort of game at your meetings?

14 Champollion \& Sauerland's aim is to explain the embedded definite in expressions like the rabbit in the hat (Haddock 1987). Here the hat is felicitous even in a context with many hats, provided that there is just one with a rabbit in it. Their hypothesis is, definites undergo QR and "accommodate" into their restriction the presuppositions of their scope. When the hat undergoes QR, its scope includes the rabbit in $x$. The presupposition of this, that there is just one rabbit in $x$, then further restricts the hat. It comes to be understood as 'the unique $x$ such that $x$ is a hat and there is just one rabbit in $x$.' Narrowed down in this way, the uniqueness condition of the description is satisfied. But in two ways, this suggestion is not broad enough to cover all the data discussed in this paper, it seems to me. First, domains are narrowed by content from higher clauses. And second, as I argue in the next paragraph of the main text, it is not just the presuppositions of the anaphor's context that restrict its domain. 
the referential domains for (41). But this inference does not express a presupposition, since (45a) and (45b) do not entail (46), which is here just a defeasible implicature. Nonetheless, it would normally be pointless to demand that X not take Y out of something it is not already in, as the demand is satisfied too easily.

$$
\mathrm{X} \text { took } \mathrm{Y} \text { out of } \mathrm{Z} \text {. }
$$

a. $\mathrm{X}$ did not take $\mathrm{Y}$ out of $\mathrm{Z}$.

b. If $\mathrm{X}$ takes $\mathrm{Y}$ out of $\mathrm{Z}$, shoot him.

$Y$ was in $Z$.

Likewise if $\mathrm{X}$ thinks that $p$, then $\mathrm{X}$ has been in a position to entertain $p$ and judge $p$ true. This restricts the domain for NCA in (29). But it is not a presupposition, since it does not survive negation or conditionalization. Nonetheless, it would normally be pointless to say that $\mathrm{X}$ does not think that $p$, unless $\mathrm{X}$ had been in a position to entertain or judge whether $p$. Baby Jo does not think that Tipper loves Ozzy, but normally such truths are not worth asserting. Similarly, if X votes for Y, then X is an eligible voter, and this shapes the domain for the subject of (43). But it is not a presupposition: Baby Jo did not vote for Y, but that does not mean she was eligible.

So the contribution of sentential context is broader than either presuppositions or selectional restrictions. Normally it also includes the 'preconditions' of the predicate sentential predicate $S$, such as the precondition of 'take Y out of Z' that Y first be in $Z$. These are entailments that do not survive negation, but whose falsity would normally (though not always) render pointless any speech act with content $\neg S x$. For now I leave open the challenge of saying anything more precise.

\section{Antecedents for NCA with notice verbs}

We have seen cases where NCA, even when not exophoric, does not need an explicit antecedent. These might be seen as instances of a broader generalization, discussed in Hankamer \& Sag 1976 and Grimshaw 1979. In general the antecedent need not match the form that an overt dependent would take, (47).

(47) a. Lee stole a book, and I don't approve (*that Lee stole a book).

b. Syl wants to know the name of the suspect, but Ro doesn't care (*the name of the suspect).

But some NCA predicates are different, and are sensitive to the expression that provides them with their referent. Among these are notice, find out, and forget. I do not know exactly which other predicates pattern with these. But for simplicity I will take my initial examples as representative, and speak of the 'notice verbs' as a class.

Verbs in this class can have a finite declarative clause as a direct object, (48). In that environment they express a relation to the proposition expressed by that clause. 
NCAs as Definite Descriptions

Mo noticed that Jo's nose was broken.

With NCA they also express a relation to a proposition. A felicitous use of (49) relates Mo to a certain proposition. In this way (49) is like (48) and not like (50). The latter relates Mo, not to a proposition, but to an object. ${ }^{15}$

Mo noticed.

(50) Mo noticed Jo's nose.

With these verbs, the notice verbs, a clause provides an acceptable antecedent for NCA. Both (51b) and (52) can be understood the same way with or without the parenthesized complement (see Dowty 1981; Partee 1989).

(51) a. Did you know that the Earth is spherical?

b. Yes, I noticed (that the Earth is spherical).

Every man who knows that the Earth is spherical hopes that his kids won't notice (that the Earth is spherical).

But a nominal antecedent is degraded in comparison. Omission of the demonstratives in (53b) and (54b) is odd, if our intention is to refer to the proposition that the Earth is spherical, or to the proposition that the Earth is not flat. Omission of the pronouns in (55) and (56) is worse.

(53) a. Were you aware of the sphericality of the Earth?

b. Yes I noticed ??(that).

a. Were you aware of the Earth not being flat?

b. Yes I noticed ??(that).

(55) Every man who is aware of the Earth's sphericality hopes that his kids won't notice ?*(it).

(56) Every man who is aware of the Earth not being flat hopes that his kids won't notice ?*(it).

Thus verbs like notice differ from ready or win, start or apply. For the latter predicates it is enough that a suitable referent be readily inferred given the context. But this alone is not enough for verbs like notice. No matter what sort of referent

15 To see this, consider (ib) in response to (ia). With a pronoun this has the sensible meaning 'I noticed Jo's nose, but didn't see anything unusual.' But with NCA it does not. It seems to say, paradoxically, 'I noticed that something is up with Jo's nose, but didn't see anything unusual.'

(i) a. What is up with Jo's nose?

b. I noticed \#(it), but didn't see anything unusual. 
the Earth's sphericality may actually have_-proposition, state of affairs, situation, trope, whatever-successful reference to the Earth's sphericality surely warrants the inference that the Earth is spherical. Yet this inference fails to support NCA in either (53b) or (55). In this way NCA with notice verbs is not like reference with a definite description. Accordingly, it must somehow be distinguished from NCA with predicates like win or ready. The question is how.

The ideal answer ought also to account for a second contrast. Verbs like notice differ from others in the availability of bound readings. As observed above, bound readings with win and ready are easy; they are available either with a pronoun or with NCA, as in (16) and (17). But notice verbs are strikingly different. The bound reading that comes easily with (57) is difficult or impossible with (58).

Nothing was forgotten by the person who had first noticed it.

The problem for bound readings is not a general ban on binding a variable that is entailed to stand for a proposition. In (59) and (60) the quantifiers bind the object of find out, and any sentence $X$ finds out $Y$ entails that $Y$ names a proposition. One can find out that a restaurant is good, but one cannot find out a restaurant.

(59) I wish that nothing would ever be found out by the enemies of those who first notice *(it).

(60) Nothing I found out seemed interesting to others who had already noticed $*(\mathrm{it})$.

Nor is the problem disharmony in information structure. (61) is parallel to (59), both in syntax and in information structure. The difference is that in (61) the antecedent for notice is an overt clause. And now NCA is fine.

Fortunately, that Batman is Bruce Wayne was never found out, even by the close friends of those who had noticed (it/this).

So the distinction is twofold. NCA with the notice class both resists bound readings and when anaphoric requires a certain sort of antecedent.

This pattern would have an account, if NCA with notice verbs could be treated as ellipsis (copying or deletion under identity) of something with sentential structure, either a clause or a formula at a level of 'semantic representation', between syntax and the domain of interpretation (Williams 1977; Grimshaw 1979). For we can assume that a noun phrase will provide no such thing, neither as an antecedent nor as a binder. Noun phrases are not clauses. And if there is a level of semantic representation-distinct from the syntax, and something like a translation into the predicate calculus-we can assume that noun phrases do not correspond to 'sentential' formulas at that level. So no noun phrase could antecede or bind NCA 
with notice verbs. The twofold contrast with win, ready and the others would in turn be explained by assuming that these do not involve any sort of ellipsis.

But there are problems with both versions of the ellipsis hypothesis. The syntactic version goes against the consensus that NCA is not copying or deletion of a clause (Hankamer \& Sag 1976; Grimshaw 1979; Depiante 2000). The evidence includes data like (62) versus (63). There can be no extraction out of an NCA, (62b), while in agreed cases of ellipsis there can be, (63b). This strikes me as decisive.

(62) a. Who have the investigators found out was lying?

b. It's much more important who you have found out *(was lying).

a. Who have the investigators found out was lying?

b. It's much more important who you have (found out was lying).

The second version of the ellipsis theory, pursued influentially in Grimshaw 1979, grants that NCA does not involve copying or deletion of syntactic structure. But it requires a level of semantic representation that is distinct from the syntax (and so is not LF as standardly conceived). This is a postulate I am reluctant to accept.

With ellipsis ruled out, let's turn to the standard analysis. Perhaps NCA with notice verbs has the semantics of a pronoun, introducing a free variable. On its own this will explain nothing. For instance, it will not explain why bound readings are unavailable to NCA with notice verbs, since they are available to pronouns. But it might be part of an explanation, if supplemented with a semantic conjecture. Suppose that the domain of reference for NCA with notice verbs comprises the things of type $k$, and that, while clauses have $k$ 's in their domain, noun phrases do not. A variable over $k$ 's will need a context to provide a $k$, or a binder whose domain includes the $k$ 's. So it will then follow that a noun phrase can neither antecede nor bind an NCA of this variety. This would explain both aspects of the contrast with win or ready - if on the grounds of a strange semantic premise.

Mo noticed none of the things that Lee had found out earlier.

What might $k$ be? One possibility is the class of propositions. Then (pace Vendler 1967 and many others) nominals never denote a proposition, but only some

15 Even if this semantics is right, (i) shows a pragmatic difference between notice NCA and pronouns. In (ia), two instances of NCA can be understood as having different antecedents. Maybe Mo's hairdresser noticed that she started to shampoo less often, but her doctor did not notice that she stopped taking her medicine. But (ib) is not so easily read this way when instead it has two pronouns, or two demonstratives. Then there is pressure to give both the same antecedent, as in (20).

(i) a. Mo started to shampoo less often, and stopped taking her medicine.

b. Her hairdresser noticed (this/that/it), but her doctor did not notice (this/that/it). 
correlate of a proposition, such as a state of affairs or a trope. A second possibility is that $k$ comprises structured propositions, tuples of individuals and properties. Then noun phrases may stand for propositions, but never structured propositions. And of course there are further possibilities, beyond these two. I don't know which is the most plausible. But no matter the answer, the theory demands a subtlety in the ontology of reference that, if interesting, is nonetheless tenuous. ${ }^{16}$ So I await a more satisfactory response to the puzzle, or new data that will dissolve it.

\section{Conclusion}

With many predicates, such as ready or win, NCA is like a definite description and not like a pronoun. Pronouns are interpreted as containing (or being) a free variable. To distinguish NCA descriptions I proposed that they are not. They have the same interpretation in every context, a description with no descriptive content. This raises the question of how to restrict their reference, while preserving their distinctness from pronouns. I suggested this be done by relativizing the domain in which they are evaluated to the sentential predicate, and observed in support of this that descriptions are more receptive of such guidance than are pronouns. But this is no more than a preliminary sketch. The theoretical execution of my suggestions remains fairly open. Importantly, they presuppose a substantial distinction between reference conditions stated in the meaning of an expression, versus a conventionalized sensitivity to restrictions on its domain of evaluation. They also presuppose that a referring expression needn't have the same domain of evaluation as other parts of its sentence. But all this is very contentious (Bach 1994a; Cooper 1996; Stanley \& Szabó 2000; Recanati 2004; Neale 2004; Lepore 2004; Elbourne 2005), and will need to be engaged in earnest on another occasion. I also leave open a new puzzle. Like a pronoun and unlike a definite description, NCA with verbs like notice is particular about its antecedent. But unlike either a pronoun or a description, it resists bound readings in quantified contexts. This hints at a difference between the semantic values of clauses and seemingly propositional noun phrases.

16 If our only interest were to explain the asymmetry in bound readings for notice verbs versus the others, we might entertain a difference in syntax. Suppose that NCA with notice involves no empty category in the syntax (Hankamer \& Sag 1976; Grimshaw 1979). We could then wager that binding requires a syntactic category that is interpreted as bound (see Stanley 2000). This would directly explain the absence of bound readings for NCA with verbs like notice. But it would also entail that there is a bound empty category with, for example, win and ready in (16) and (17). And while this implied distinction is reasonable, I know of no further evidence in its favor. 
NCAs as Definite Descriptions

\section{References}

Bach, Kent. 1994a. Conversational impliciture. Mind and Language 9. 124-162. doi:10.1111/j.1468-0017.1994.tb00220.x.

Bach, Kent. 1994b. Semantic slack: What is said and more. In Savas L. Tsohatzidis (ed.), Foundations of Speech Act Theory, 267-291. New York: Routledge.

Barwise, John \& Robin Cooper. 1981. Generalized Quantifiers and Natural Language. Linguistics and Philosophy 4(1). 159-219. doi:10.1007/BF00350139.

Champollion, Lucas \& Uli Sauerland. 2011. Move and accommodate: A solution to Haddock's puzzle. In O. Bonami \& P. Cabredo Hofherr (eds.), Empirical Issues in Syntax and Semantics 8, 27-51. http://www.cssp.cnrs.fr/eiss7/.

Condoravdi, Cleo \& Jean-Marc Gawron. 1996. The context-dependency of implicit arguments. In Makoto Kanazawa, Christopher Pinon \& Henriëtte de Swart (eds.), Quantifiers, Deduction, and Context, 1-32. Stanford, CA: CSLI Publications.

Cooper, Robin. 1979. The interpretation of pronouns. In Frank Heny \& Helmut Schnelle (eds.), Syntax and Semantics, Volume 10: Selections from the Third Groningen Round Table, 61-92. New York: Academic Press.

Cooper, Robin. 1996. The role of situations in Generalized Quantifiers. In Shalom Lappin (ed.), The Handbook of Contemporary Semantic Theory, 65-86. Malden, MA: Blackwell Publishers.

Dale, Robert \& Nicholas Haddock. 1991. Content determination in the generation of referring expressions. Computational Intelligence 7(4). 252-265. doi:10.1111/j.1467-8640.1991.tb00399.x.

Depiante, Marcela. 2000. The syntax of deep and surface anaphora: University of Connecticut at Storrs dissertation.

Dowty, David. 1981. Quantification and the lexicon. In Michael Moortgat, Harry van der Hulst \& Teun Hoekstra (eds.), The Scope of Lexical Rules, 79-106. Dordrecht: Foris Publications.

Elbourne, Paul. 2005. Situations and Individuals. Cambridge, MA: The MIT Press.

Elbourne, Paul. 2010. The existence entailments of definite descriptions. Linguistics and Philosophy 33(1). 1-10. doi:10.1007/s10988-010-9072-3.

Evans, Gareth. 1982. The Varieties of Reference. New York: Oxford University Press.

Fillmore, Charles. 1971. Types of lexical information. In Danny D. Steinberg \& Leon A. Jakobovits (eds.), Semantics, 370-392. Cambridge: Cambridge University Press.

Fillmore, Charles. 1986. Pragmatically controlled zero anaphora. Berkeley Linguistics Society (BLS) 12.95-107.

Francez, Itamar. 2010. Context dependence and implicit arguments in existentials. Linguistics and Philosophy 33. 11-30. doi:10.1007/s10988-010-9073-2. 
Gauker, Christopher. 2012. What is Tipper ready for? A semantics for incomplete predicates. Noûs 46(1). 61-85. doi:10.1111/j.1468-0068.2010.00782.x.

Gillon, Brendan. 2006. English relational words, context sensitivity and implicit arguments. McGill University manuscript.

Gillon, Brendan. 2011. Implicit arguments: A dilemma for model-theoretic semantics. McGill University manuscript.

Grimshaw, Jane. 1979. Complement selection and the lexicon. Linguistic Inquiry 10(2). 279-326.

Haddock, Nicholas. 1987. Incremental interpretation and Combinatory Categorial Grammar. International Joint Conference on Artificial Intelligence (IJCAL'87) 10. 661-663.

Hankamer, Jorge \& Ivan Sag. 1976. Deep and surface anaphora. Linguistic Inquiry 7(3). 391-428.

Heim, Irene. 1990. E-type pronouns and donkey anaphora. Linguistics and Philosophy 13(2). 137-177. doi:10.1007/BF00630732.

Heim, Irene. 1991. Artikel und Definitheit. In Arnim von Stechow \& Dieter Wunderlich (eds.), Semantik: Ein internationales Handbuch des zeitgenossischen Forschung, 487-535. Berlin: Walter de Gruyter.

Heim, Irene \& Angelika Kratzer. 1998. Semantics in Generative Grammar. Malden, MA: Blackwell Publishers.

Koenig, Jean-Pierre \& Gail Mauner. 2000. A-definites and the discourse status of implicit arguments. Journal of Semantics 16. 207-236. doi:10.1093/jos/16.3.207.

Lepore, Ernie. 2004. An abuse of context in semantics: The case of incomplete definite descriptions. In Marga Reimer \& Anne Bezuidenhout (eds.), Descriptions and Beyond, 15-40. New York: Oxford University Press.

Lewis, David. 1979. Score-keeping in a language game. Journal of Philosophical Logic 8. 339-359. doi:10.1007/BF00258436.

McCawley, James. 1979. Presupposition and discourse structure. In David Dinneen \& Choon Kyu Oh (eds.), Syntax and Semantics, Volume 11: Presupposition, 371-388. New York: Academic Press.

ter Meulen, Alice G.B. 2004. Dynamic definite descriptions, implicit arguments, and familiarity. In Marga Reimer \& Anne Bezuidenhout (eds.), Descriptions and Beyond, 544-557. New York: Oxford University Press.

Neale, Stephen. 1990. Descriptions. Cambridge, MA: The MIT Press.

Neale, Stephen. 2004. This, that, and the other. In Marga Reimer \& Anne Bezuidenhout (eds.), Descriptions and Beyond, 68-188. New York: Oxford University Press.

Partee, Barbara. 1989. Binding implicit variables in quantified contexts. Chicago Linguistic Society (CLS) 25. 342-356.

Pedersen, Walter. 2011. Implicit arguments, paychecks, and variable-free semantics. 
NCAs as Definite Descriptions

Semantics and Linguistic Theory (SALT) 21. 155-175.

Prince, Ellen F. 1981. Towards a taxonomy of given-new information. In Peter Cole (ed.), Radical Pragmatics, New York: Academic Press.

Recanati, François. 2004. Descriptions and situations. In Marga Reimer \& Anne Bezuidenhout (eds.), Descriptions and Beyond, 15-40. New York: Oxford University Press.

Shopen, Tim. 1973. Ellipsis as grammatical indeterminacy. Foundations of Language 10(1). 65-77.

Stanley, Jason. 2000. Context and logical form. Linguistics and Philosophy 23(4). 391-434. doi:10.1023/A:1005599312747.

Stanley, Jason \& Zoltán Gendler Szabó. 2000. On quantifier domain restriction. Mind and Language 15(2/3). 219-261. doi:10.1111/1468-0017.00130.

Stone, Matthew \& Bonnie Webber. 1998. Textual economy through close coupling of syntax and semantics. International Conference on Natural Language Generation (INLG) 98. 178-187.

Vendler, Zeno. 1967. Linguistics in philosophy. Ithaca: Cornell University Press.

Westerståhl, Dag. 1985. Determiners and context sets. In Johan van Bentham \& Alice G.B. ter Meulen (eds.), Quantification in Natural Language, 45-71. Dordrecht: Foris Publications.

Williams, Edwin. 1977. Discourse and logical form. Linguistic Inquiry 8(1). $101-139$.

Alexander Williams

1401 Marie Mount Hall

College Park, MD

alxndrw@umd.edu 